Editorial

\title{
Fiber-Reinforced Cement Composites: Mechanical Properties and Structural Implications
}

\author{
Doo-Yeol Yoo $\left(\mathbb{D}^{1},{ }^{1}\right.$ Nemkumar Banthia $\left(\mathbb{D},{ }^{2}\right.$ Kazunori Fujikake, ${ }^{3}$ Young Hoon Kim, \\ and Rishi Gupta ${ }^{5}$ \\ ${ }^{1}$ Department of Architectural Engineering, Hanyang University, 222 Wangsimni-ro, Seongdong-gu, Seoul 04763, \\ Republic of Korea \\ ${ }^{2}$ Department of Civil Engineering, The University of British Columbia, 6250 Applied Science Lane, Vancouver, BC, \\ CanadaV6T $1 Z 4$ \\ ${ }^{3}$ Department of Civil and Environmental Engineering, National Defense Academy, Yokosuka 239 8686, Japan \\ ${ }^{4}$ Department of Civil and Environmental Engineering, University of Louisville, Louisville, KY 40292, USA \\ ${ }^{5}$ Department of Civil Engineering, University of Victoria, 3800 Finnerty Road, Victoria, BC, CanadaV8W 2 Y2
}

Correspondence should be addressed to Doo-Yeol Yoo; dyyoo@hanyang.ac.kr

Received 13 March 2018; Accepted 13 March 2018; Published 24 June 2018

Copyright (C) 2018 Doo-Yeol Yoo et al. This is an open access article distributed under the Creative Commons Attribution License, which permits unrestricted use, distribution, and reproduction in any medium, provided the original work is properly cited.

To overcome inherent brittleness of concrete, extensive research on the development of high-ductility fiber-reinforced cement composites (FRCCs) has been conducted so far. Several types of FRCCs incorporating metallic, polymeric, carbon, glass, nylon, and waste tire fibers were successfully developed and effectively applied for infrastructure (i.e., buildings, tunnels, and bridges) because of their benefits of limiting crack propagation and widening through fiber bridging. Furthermore, (ultra-) high-performance fiber-reinforced cement composites showing strain- or deflection-hardening behavior with formation of multiple microcracks were invented in recent years, and various relevant studies are actively underway.

This special issue aims to give a comprehensive overview on FRCCs, including aspects related to mechanical behaviors, strengthening performance, and structural implications under various loading conditions (i.e., quasistatic, impact, blast, and fire). The selection of papers in this special issue was also very rigorous.

A several number of experimental and numerical papers reported new research findings regarding the mechanical properties of FRCCs. R. Fediuk et al. have studied to create a high-density impermeable FRCC and proposed the optimum binder proportions of $55 \mathrm{wt} . \%$ of ordinary Portland cement, 40 wt. $\%$ of fly ash, and 5 wt. $\%$ of limestone crushed wastes. Based on this optimization process, the FRCC with a high compressive strength of about
$100 \mathrm{MPa}$ and diffusion coefficient of about $1.36 \cdot 10^{-4} \mathrm{~cm}^{2} / \mathrm{s}$ was successfully developed. Y. Yang et al. have examined the effect of $\mathrm{CaCO}_{3}$ whisker on the mechanical properties of cement paste. In their study, the optimum dosage of the $\mathrm{CaCO}_{3}$ whisker was suggested to be $10 \%$, which most significantly enhanced the tensile strength of cement paste. In addition, various mechanical properties, such as the peak strength, elastic modulus, and energy absorption capacity of the cement composites with $\mathrm{CaCO}_{3}$ whisker, were reinforced with an increase in the amount of $\mathrm{CaCO}_{3}$ whisker. J.-H. Lee et al. have assessed various mechanical properties and durability of latex-modified FRCCs with polyolefin-based macrosynthetic fibers and hybrid macrosynthetic-polypropylene fibers for tunnel lining application. They have concluded that the hybrid FRCCs exhibit the better mechanical performance and durability in terms of the higher compressive strength, flexural strength, impact resistance, abrasion resistance, and resistance to chloride ion penetration as compared to the macrosynthetic FRCCs. In order to develop a low-cost FRCC using various cellulose fibers, A. M. Soydan et al. have performed several mechanical tests. Based on the experimental results, they noted that the mechanical properties, that is, modulus of rupture and elastic modulus of FRCCs with blenched eucalyptus and araucaria cellulose fibers, are superior to those with cropped virgin cellulose fibers, especially after long air-cure 
cycles, due to the higher density and packing of the formers. H. Deng and S. Qian have investigated the feasibility of using local ingredients for making high-early-strength engineered cementitious composites (ECCs) for rapid repair of existing transportation infrastructures. They reported that, by using the $0.8 \%$ local polyethylene fibers, the high-early-strength ECC with a tensile strength of $2.5 \mathrm{MPa}$ and tensile strain capacity of 3\% within 6 hours was successfully developed. This material can also lead to the ultimate compressive and tensile strengths of 49 and $5 \mathrm{MPa}$, respectively, and the ultimate tensile strain capacity of $3.5 \%$ after 60 days. The cost of all ingredients was greatly saved up to $70 \%$ by using the domestic products. K. Tereza et al. have evaluated various physicomechanical properties of steel fiber-reinforced concrete (SFRC) and noted that the flexural and residual strengths were improved by increasing the amount of steel fibers, and also, X. Y. Wang have suggested kinetic hydration heat models of high-performance concrete containing limestone powder.

Several researchers have investigated strengthening and repairing systems of existing structures using FRCCs. S. Lee et al. evaluated the flexural performance of reinforced concrete (RC) slabs strengthened with basalt fabric FRCCs. Based on their test results, the load carrying capacity of ordinary RC slab was improved as much as 11.2 to $98.2 \%$ by strengthening it with basalt fabric FRCCs, but the energy ratio and ductility were reduced with increasing the amount of fabric and tensile steel reinforcement, changing the ductile failure mode to the brittle failure mode. W. Kim et al. have examined the effects of reinforcing fibers and microsilica contents on the properties of latex-modified FRCCs for pavement repair. They recommended to use the microsilica at a substitution ratio of $3 \%$ or less and the macrosynthetic fibers as the reinforcement for the performance of latexmodified FRCCs for emergency repair of concrete pavement and to satisfy all the target strength requirements. J. Moon et al. have studied to evaluate a feasibility of hybrid fiberreinforced polymer (FRP) and ultra-high-performance concrete (UHPC) system for flexural strengthening of RC slabs. This proposed strengthening system could improve the ultimate load carrying capacity of the RC slab by $70 \%$, the stiffness by $60 \%$, and the toughness by $128 \%$, and also, the effectiveness of shear connectors on ductile behavior of the strengthened RC slab was confirmed. Lastly, W. Choi et al. have studied to decrease the lap-spliced length of reinforcement using a polyethylene FRCC showing strain-hardening response. They have verified that, by using the polyethylene FRCC, the development length of lap splice was effectively reduced as much as $60 \%$ of the splice length recommended by ACI 318-11 code, and the addition of expansive admixture to the FRCC mixture enhanced the initial performance and mitigated the cracking behavior in the lap splice region.

We hope that readers of this special issue are able to obtain useful experimental and numerical results and discover some recent research trends with regard to the FRCCs. We also wish that the readers' academic curiosities are satisfied and research questions are solved based on the valuable research results in this special issue from experimental and numerical findings. This publication considers a wide range of disciplines, which include civil, architectural, and construction materials engineering, and may appeal to the engineers and scientists.

\author{
Doo-Yeol Yoo \\ Nemkumar Banthia \\ Kazunori Fujikake \\ Young Hoon Kim \\ Rishi Gupta
}




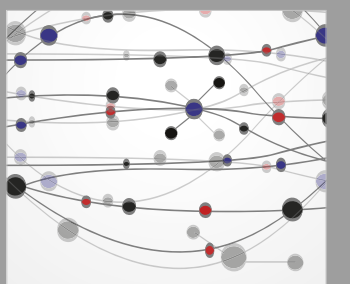

The Scientific World Journal
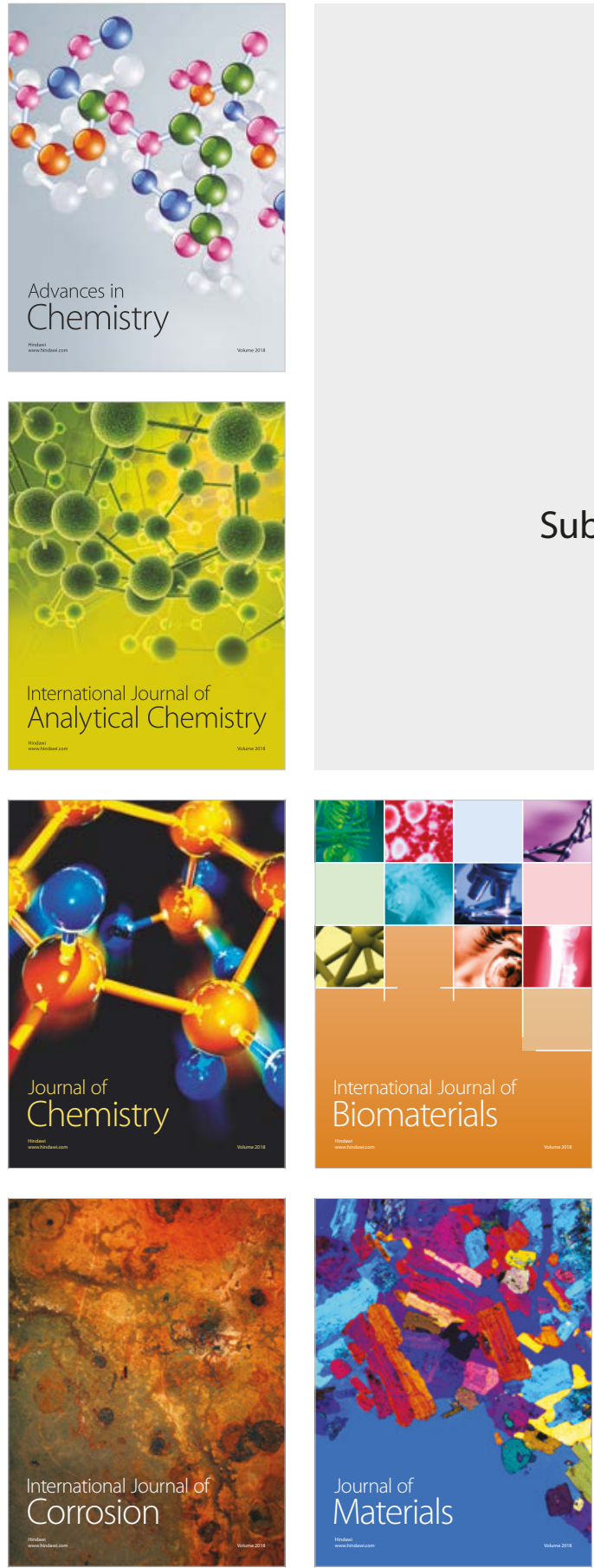

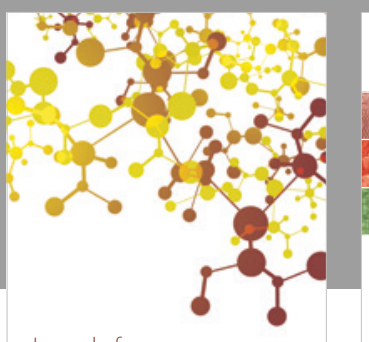

Journal of

Applied Chemistry
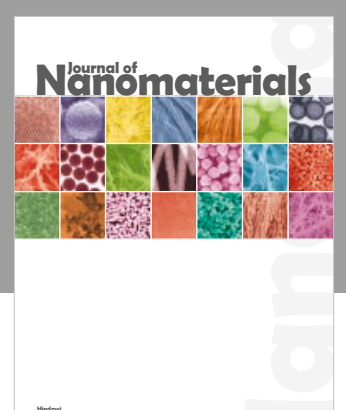

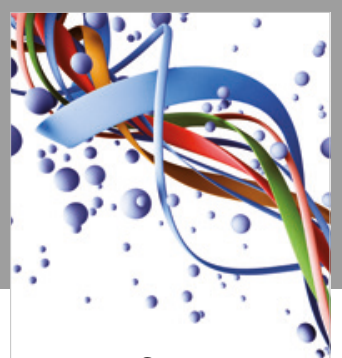

Scientifica

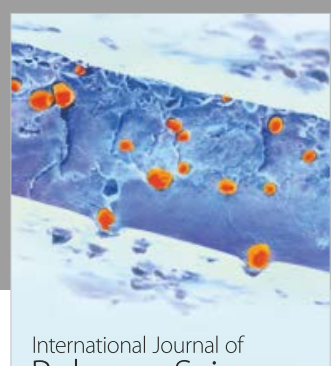

Polymer Science

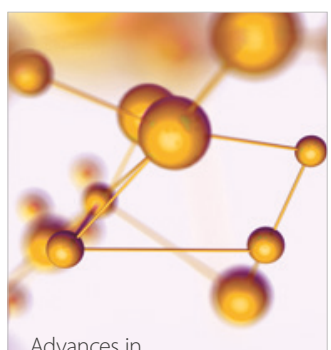

Physical Chemistry
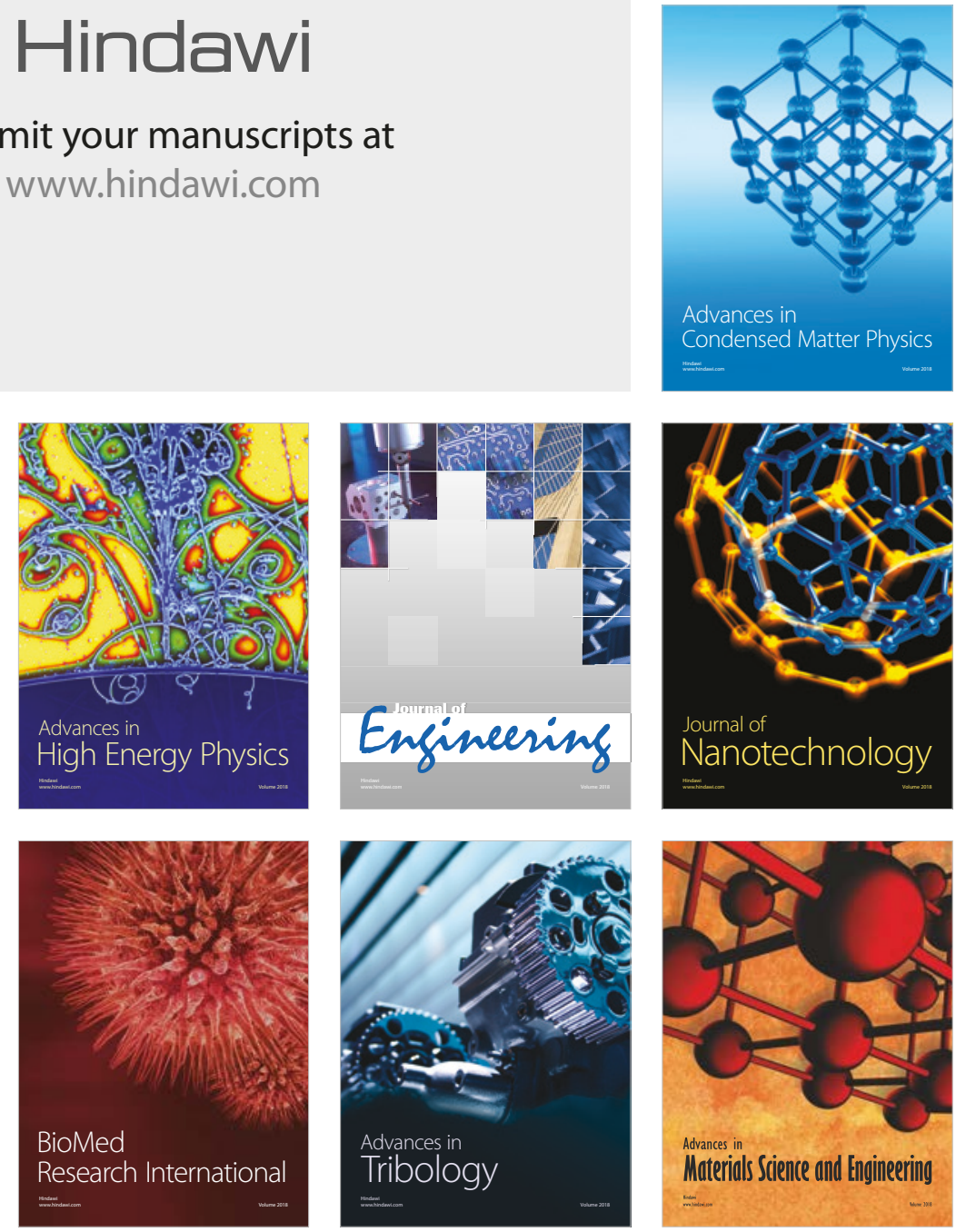